\title{
Numerical Verification of B-WIM System Using Reaction Force Signals
}

\author{
Sung-Jin Chang* and Nam-Sik Kim* ${ }^{\dagger}$
}

\begin{abstract}
Bridges are ones of fundamental facilities for roads which become social overhead capital facilities and they are designed to get safety in their life cycles. However as time passes, bridge can be damaged by changes of external force and traffic environments. Therefore, a bridge should be repaired and maintained for extending its life cycle. The working load on a bridge is one of the most important factors for safety, it should be calculated accurately. The most important load among working loads is live load by a vehicle. Thus, the travel characteristics and weight of vehicle can be useful for bridge maintenance if they were estimated with high reliability. In this study, a B-WIM system in which the bridge is used for a scale have been developed for measuring the vehicle loads without the vehicle stop. The vehicle loads can be estimated by the developed B-WIM system with the reaction responses from the supporting points. The algorithm of developed B-WIM system have been verified by numerical analysis.
\end{abstract}

Keywords: B-WIM System, Influence Line, Numerical Analysis, Reaction Force Responses, Vehicle Load

\section{Introduction}

Bridges are ones of the major facilities of the road which constitutes the core of the social overhead capital facilities. That is why they are designed to ensure their safety during their use. If the construction work is trustworthy and there is no change of materials and environments, they can be used safely during their design fatigue life. But as time passes, bridges are damaged due to changes of travel characteristics or other exterior environments. Therefore, it is needed to verify the damages inflicted on the bridges and to ensure their safety through maintenance and management.

It is important to exactly calculate the working load on a bridge for verifying damages which can be caused by the working load as dead load and live load(vehicle load, wind load, seismic load). It easy to predict damages due to dead load because the dead load is not changed much after construction. Therefore live load on a bridge should be measured for evaluating the safety of the bridge. In the case of normal road bridges excepted the cable supported bridges, the vehicle load is one of the most important load which is working on the bridges. Thus, the travel characteristics and weights of vehicles can be useful for bridge maintenance if they were estimated with high reliability.

WIM (weigh in motion) system [1] and B-WIM (bridge weigh in motion) system are the two typical systems for measuring the vehicle load. Total load and axial load of vehicle can be measured with an WIM system in which an axle weight sensor were installed. It could be hard to measure vehicle load in an WIM system because of errors which can be occurred by the interaction between road surface and vehicles. Moreover, the measured signals may be distorted due to destruction or distortion of pavement materials. In addition, normal WIM systems have a weakness of inefficiency for traffic because the vehicle should be slowly passed the bridge for exact measurement.

In a B-WIM system, the bridge is used for a scale to measure vehicle loads instead of direct measurement. There were many studies

[Received: October 22, 2012, Revised: November 30, 2012, Accepted: December 5, 2012] *Department of Civil \& Environmental Engineering, Pusan National University, Busan 609-735, Korea †Corresponding Author: nskim@pusan.ac.kr

(c) 2012, Korean Society for Nondestructive Testing 
for measurement of vehicle load using bridge. A B-WIM system using strain gauges and axial detector was developed for estimation of vehicle load [2]. And a time domain vehicle load estimation algorithm based on the equations of motion was developed by Law et al. [3]. There are studies for analyzing the travel characteristics of heavy vehicles using the B-WIM system [4] and for identifying live load and fatigue load on high-way bridges [5]. A study was executed to analyze the vehicle load on a cable-stayed bridge using the B-WIM system [6] and the sensitivity-based B-WIM system using dynamic strain responses of bridge deck plate was applied in another study [7]. Moreover, another B-WIM algorithm using density estimation function and average modification factor was developed by Han et al. [8].

Moses developed a B-WIM system which utilizes strain sensors and piezo sensors. Many sensors should be installed on a bridge for measuring vehicle speed and vehicle load in the system. And it is hard to maintain the system, because the axial sensors are installed in the pavement layer. In addition, the usability of the B-WIM system is limited to simple slab bridges, slab bridges fixed at both ends or other bridges with similar effect.

In this study, authors have developed a B-WIM system which utilizes a reaction force at bridge supporting points. A vehicle load can be estimated with reaction force responses of supporting points by the developed B-WIM system. And verification of the developed B-WIM system was executed with numerical analysis of a single-span bridge and a 3-span continuous bridge.

\section{B-WIM System}

The reaction forces at bridge supporting

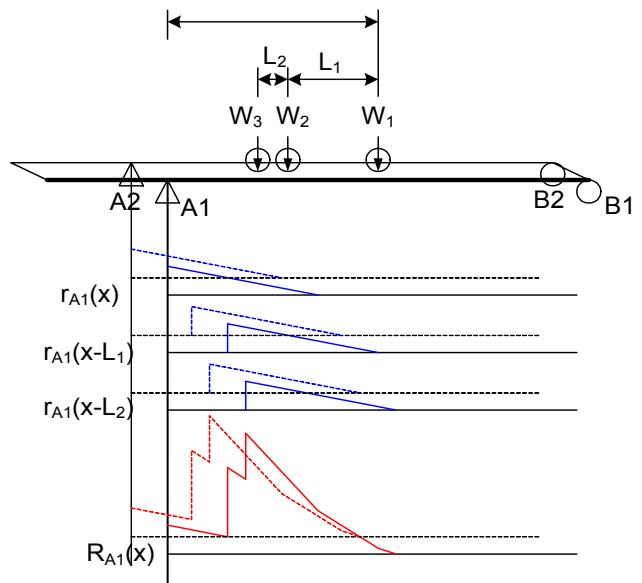

Fig. 1 Influence line of reaction force at supporting point

points are used in the developed B-WIM system in this study. Fig. 1 shows the influence lines of reaction force at supporting point.

The reaction force responses at supporting points can be numerically expressed as Eq. (1) with influence lines of reaction forces from supporting points as shown in Fig. 1. In the Eq. (1), $R(x)$ represents reaction force, $W_{n}$ is the weight at the nth axis, and $r(x)$ is the influence line at vehicle position $x$ on the bridge. Vehicle speed can be estimated with Eq. (2) because vehicle' entry time and exit time are estimated from reaction force response. In the Eq. (2), $L$ is the distance between supporting points of bridge, and $\Delta T$ represents the passing time for a vehicle axis between the two supporting points.

$$
\begin{aligned}
& R(x)=W_{1} r(x)+W_{2} r\left(x-L_{1}\right)+W_{3} r\left(x-L_{2}\right) \\
& v=\frac{L}{\triangle T}
\end{aligned}
$$

Number of impact in reaction force response signals means the number of vehicle axes, and the wheel bases can be expressed as equation (3). In the Eq. (3), $l_{A B}$ is the distance between the $\mathrm{A}$ axis and the $\mathrm{B}$ axis of the vehicle, and 
$\triangle t_{A B}$ represents the time interval between the $\mathrm{A}$ axis and $\mathrm{B}$ axis on a supporting point.

$$
\begin{aligned}
& l_{A B}=v \times \Delta t_{A B} \\
& R_{i}(t)=\sum_{l=1}^{N L} \sum_{k}^{N a x l(l)} W_{k l} r_{k l i}(t)
\end{aligned}
$$

The reaction force response at ith supporting point can be expressed by using the reaction force due to each girder and each lane from the Eq. (1). In the Eq. (4), $W_{k l}$ represents the $k^{\prime}$ th axis weight in l'th lane, and $r_{k l i}(t)$ is the influence line value on the $i$ 'th supporting point by $k^{\prime}$ th axis on $l$ 'th lane at time $(t) . N L$ is the number of lanes, and $\operatorname{Naxl}(l)$ is the total number of axes on $l$ 'th lane. A minimum square error function is constructed as Eq. (5) by using the theoretical influence lines and the reaction forces from a numerical dynamic test at all of supporting points. In the Eq. (5), $E_{i}$ means the minimum square error function, $R_{i}(t)$ and $R_{i}^{*}(t)$ are the theoretical reaction force and the reaction force from a numerical dynamic test at $i$ 'th supporting point, respectively. Equation (6) can be driven by substituting equation (4) into Eq. (5). Also, the Eq. (6) can be transformed to Eq. (7). The Eq. (8) can be reconstructed by using $W_{n}^{*}$ and $r_{n i}^{*}(t)$ instead of $W_{k l}$ and $r_{k l i}(t)$ in Eq. (7), respectively.

$$
\begin{aligned}
& E_{i}=\sum_{t=1}^{T}\left[R_{i}(t)-R_{i}^{*}(t)\right]^{2} \\
& E_{i}=\sum_{t=1}^{T}\left[\sum_{l=1}^{N L} \sum_{k}^{\operatorname{Naxl}(l)} W_{k l} r_{k l i}(t)-R_{i}^{*}(t)\right]^{2} \\
& E=\sum_{i=1 t=1}^{N G} \sum_{t=1}^{T}\left[\sum_{l=1}^{N L} \sum_{k}^{\operatorname{Naxl}(l)} W_{k l} r_{k l i}(t)-R_{i}^{*}(t)\right]^{2} \\
& E=\sum_{i=1 t}^{N G} \sum_{t=1}^{T}\left[\sum_{n=1}^{N A} W_{n}^{*} r_{n i}^{*}(t)-R_{i}^{*}(t)\right]^{2}
\end{aligned}
$$

As the sum of error values need to be the minimum, Eq. (9) can be driven by partial differentiating Eq. (8) with respect to the m'th axis weight.

$$
\begin{aligned}
\frac{\partial E}{\partial W_{m}}= & \sum_{i=1}^{N G} \sum_{t=1}^{T}\left[\sum_{n=1}^{N A} W_{n}^{*} r_{n i}^{*}(t)\right] r_{m i}^{*}(t) \\
& -\sum_{i=1}^{N G} \sum_{t=1}^{T} R_{i}^{*}(t) r_{m i}^{*}(t)=0
\end{aligned}
$$

Eq. (9) can be expressed as Eq. (12) if Eq. (10) is the influence line value, and Eq. (11) is the reaction force.

$$
\begin{aligned}
& F_{m n}=\sum_{i=1}^{N G} \sum_{t=1}^{T} r_{n i}^{*}(t) r_{m i}^{*}(t) \\
& R_{m}=\sum_{i=1}^{N G} \sum_{t=1}^{T} R_{i}^{*}(t) r_{m i}^{*}(t) \\
& \sum_{n=1}^{N A} F_{m n} \times W_{n}^{*}=R_{m}
\end{aligned}
$$

Eq. (12) can be expressed as Eq. (13) in determinant, and Eq. (13) can be expressed as Eq. (14) in respect to axis weight $\{W\}$.

$$
\begin{aligned}
& {[F]\{W\}=\{R\}} \\
& \{W\}=[F]^{-1}\{R\}
\end{aligned}
$$

Fig. 2 shows the flowchart of the developed B-WIM system.

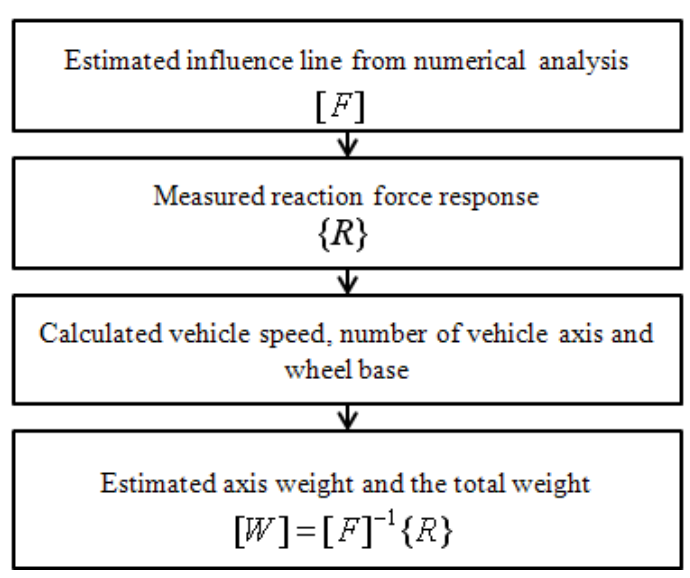

Fig. 2 Flowchart of B-WIM system algorithm 


\section{Verification of B-WIM System by Numerical Analysis Model}

3.1 Algorithm Verification by Using Numerical Analysis Model of Single-Span Bridge

\subsubsection{Bridge Model}

A numerical analysis has been performed to verify the B-WIM system developed in this study. Numerical analysis were performed under various conditions based on changing of SNR (signal to noise ratio), retardation, time delay, and vehicle speed to confirm the error rate of vehicle load estimation. A numerical model was constructed as a single-span bridge of which wide and length were $12 \mathrm{~m}$ and $40 \mathrm{~m}$, respectively. And beam and shell elements were used for the girders and slab, respectively. Fig. 3 represents the model on which the numerical analysis was performed. The dynamic characteristics (mode shape, natural frequency) are shown in Table 1.

Table 1 Dynamic characteristics of plate girder bridge (mode shape, natural frequency)

\begin{tabular}{|c|c|c|c|c|}
\hline \multirow{2}{*}{$\begin{array}{c}\text { Mode } \\
\text { No. }\end{array}$} & \multirow{2}{*}{$\begin{array}{l}\text { Frequency } \\
\text { (cycle/sec) }\end{array}$} & \multicolumn{2}{|c|}{ TRAN-Z } & \multirow[b]{2}{*}{ Mode shape } \\
\hline & & $\begin{array}{c}\text { MASS } \\
(\%)\end{array}$ & $\begin{array}{c}\text { SUM } \\
(\%)\end{array}$ & \\
\hline 1 & 4.6191 & 76.74 & 76.74 & \\
\hline 2 & 13.5833 & 0.12 & 76.86 & \\
\hline 3 & 19.0217 & 4.89 & 81.75 & \\
\hline 4 & 21.6611 & 0.12 & 81.87 & \\
\hline 5 & 22.7091 & 6.38 & 88.25 & \\
\hline
\end{tabular}

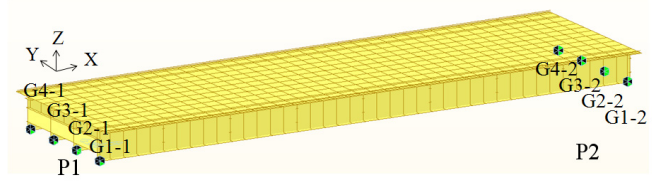

Fig. 3 Numerical analysis model (plate girder bridge)

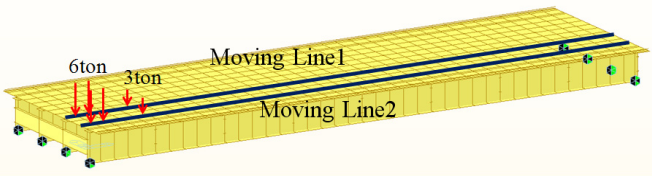

Fig. 4 Location of vehicle load

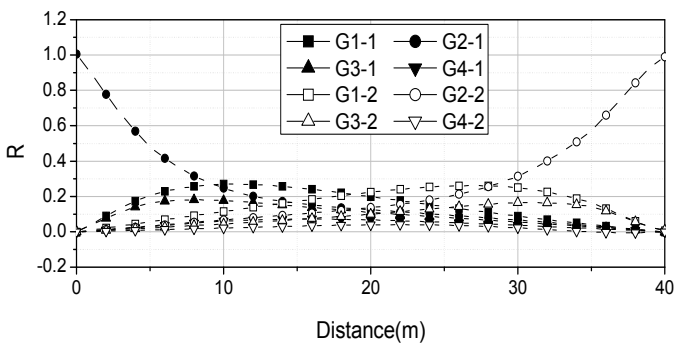

(a) Moving line1

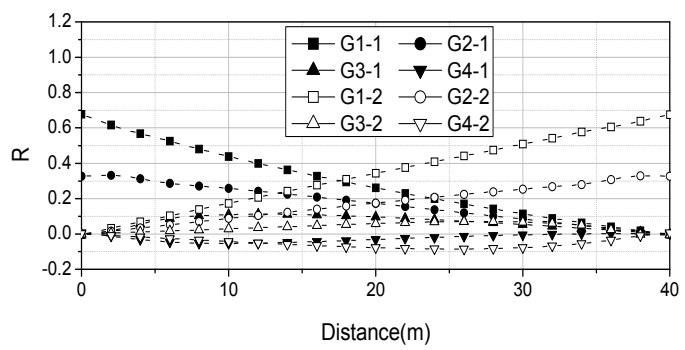

(b) Moving line2

Fig. 5 The Influence line of reaction force

Moving load analysis of two types were performed as shown in Fig. 4. The influence line of reaction force in case of moving vehicle is represented in Fig. 5. Vehicle load is estimated using the influence line of reaction force and the reaction force response of the bridge supporting points. That is why it is crucial to accurately estimate the influence line.

\subsubsection{Estimation of Vehicle Load Based on Signal to Noise Ratio}

Total load and axis load of the vehicle were estimated from the reaction force response without noise for verifying the accuracy of B-WIM system. Fig. 6 shows the reaction force reponses without noise. In the figure, $\mathrm{x}$ axis means the distance between the front axis of the vehicle and the P1 of the bridge. 


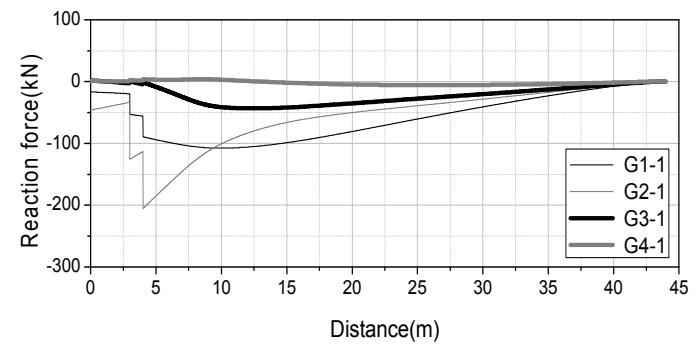

Fig. 6 Reaction force responses without noise

Table 2 Estimated vehicle load using reaction force response without noise

\begin{tabular}{ccccc}
\hline & 1st axis & 2nd axis & 3rd axis & Total \\
\hline $\begin{array}{c}\text { Vehicle } \\
\text { Load }(\mathrm{kN})\end{array}$ & 60.00 & 120.00 & 120.00 & 300.00 \\
\hline $\begin{array}{c}\text { error rate } \\
(\%)\end{array}$ & 0.000 & 0.000 & 0.00 & 0.00 \\
\hline
\end{tabular}

No error occurred when estimating the total load and axial load of the vehicle based on reaction force response without noise as shown in Table 2. Therefore, it seems possible to estimate the total load and axial load of vehicles using B-WIM system developed in this study. However, the reaction force responses from a field experiment may include some of noises caused by impact or environmental factors. To understand the relationship between the noises and vehicle load estimated by developed B-WIM system, the changes of estimated total weight and axial weight according to SNR was investigated. SNR can be expressed as Eq. (15). In the Eq. (15), $e(j)$ is the signal with noise, and $s(j)$ represents a signal without noise.

$$
S N R=10 \log _{10}\left(\frac{\sum_{j=1}^{N} s(j)^{2}}{\sum_{j=1}^{N}(e(j)-s(j))^{2}}\right) d B
$$

Fig. 7 shows the reaction forces with white noise produced according to SNR changes. The error rates of estimated vehicle loads were analyzed according to SNR.

Table 3 shows the estimated total loads and axial loads of the vehicle according to SNR. As

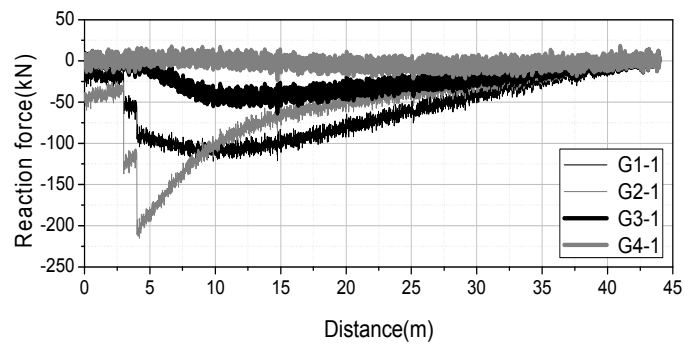

(a) $\mathrm{SNR}=20 \mathrm{~dB}$

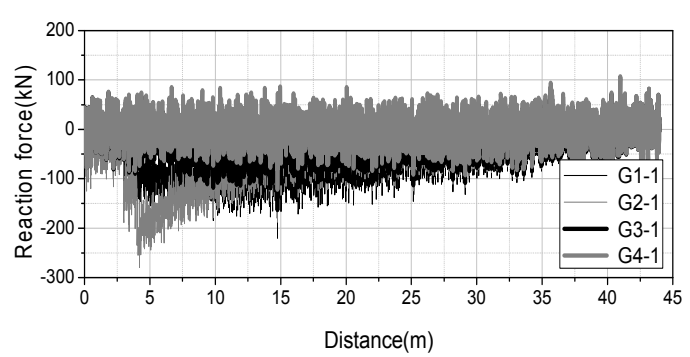

(b) $S N R=5 d B$

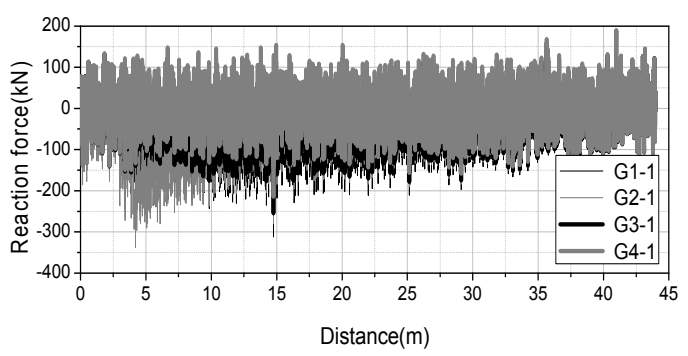

(c) $\mathrm{SNR}=0.1 \mathrm{~dB}$

Fig. 7 Reaction force response based on SNR

Table 3 Comparison of estimated vehicle load considering the influence of SNR

\begin{tabular}{|c|c|c|c|c|c|}
\hline & $\mathrm{N} / \mathrm{S}$ & 1st axis & 2nd axis & 3rd axis & Total \\
\hline \multirow[t]{2}{*}{$20 \mathrm{~dB}$} & $\begin{array}{c}\text { Vehicle } \\
\operatorname{Load}(\mathrm{kN})\end{array}$ & 60.540 & 119.903 & 120.060 & 300.503 \\
\hline & error rate $(\%)$ & 0.900 & 0.081 & 0.050 & 0.168 \\
\hline \multirow[t]{2}{*}{$10 \mathrm{~dB}$} & $\begin{array}{c}\text { Vehicle } \\
\operatorname{Load}(\mathrm{kN})\end{array}$ & 61.708 & 119.693 & 120.189 & 301.590 \\
\hline & error rate $(\%)$ & 2.847 & 0.256 & 0.157 & 0.530 \\
\hline \multirow[t]{2}{*}{$5 \mathrm{~dB}$} & $\begin{array}{c}\text { Vehicle } \\
\text { Load(kN) }\end{array}$ & 63.038 & 119.454 & 120.336 & 302.827 \\
\hline & error rate( $(\%)$ & 5.062 & 0.455 & 0.280 & 0.942 \\
\hline \multirow[t]{2}{*}{$1 \mathrm{~dB}$} & $\begin{array}{c}\text { Vehicle } \\
\operatorname{Load}(k N)\end{array}$ & 64.815 & 119.134 & 120.532 & 304.481 \\
\hline & error rate(\%) & 8.024 & 0.721 & 0.443 & 1.494 \\
\hline \multirow[t]{2}{*}{$0.1 \mathrm{~dB}$} & $\begin{array}{c}\text { Vehicle } \\
\text { Load(kN) }\end{array}$ & 65.340 & 119.040 & 120.590 & 304.970 \\
\hline & error rate $(\%)$ & 8.900 & 0.800 & 0.492 & 1.657 \\
\hline
\end{tabular}


shown in the Table 3, error rate of estimated vehicle load and axial load was decreased according to growth of SNR. Therefore, it will be possible to estimate vehicle load with less error rate by using the response signals with small noise effect.

\subsubsection{Effect of Retardation for Vehicle Load Estimation}

A retardation phenomenon should be considered in field test when a material of bridge bearing has viscoelastic property which can cause the retardation of reaction forces. In this study, data smoothing technique was used in order to express the retardation effect. Vehicle load was estimated by developed B-WIM system with distorted reaction force responses. In this study the simple moving average technique had been used which was one of date smoothing technique. In the simple moving average technique, the total average error rate can be decreased by using the average values of each sub-group separated from data in the process. The simple moving average method is explained in Eq. (16). In the Eq. (16), $d_{i}$ is the value of distorted response, and $\mathrm{N}$ is the number of data for each sub-group. Fig. 8 shows the reaction force response according to $\mathrm{N}$. The interval of reaction force response is $0.01 \mathrm{~m}$.

$$
S M A=\frac{\sum_{i=1}^{N} d_{i}}{N}
$$

As shown in Table 4, it was possible to estimate the total load and axial load of the vehicle with the distorted reaction force response in Fig. 8. In the Table 4, the errors of total load and axial load was increased according to growth of N. Therefore, it seems that the error of load estimation can be increased according to the retardation effect. However, while the estimation results of axial load were largely

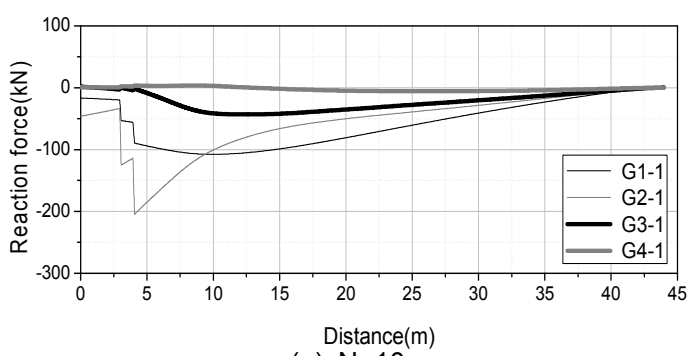

(a) $\mathrm{N}=10$

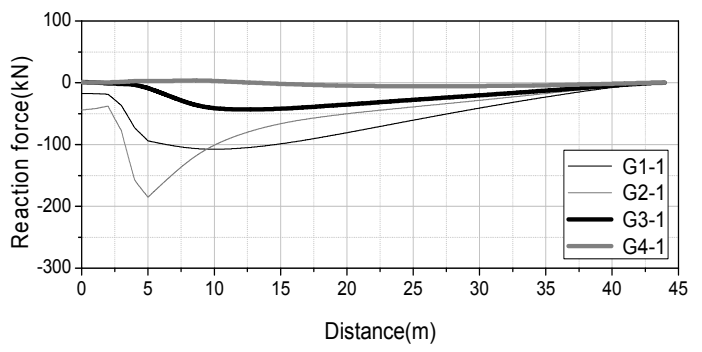

(b) $\mathrm{N}=200$

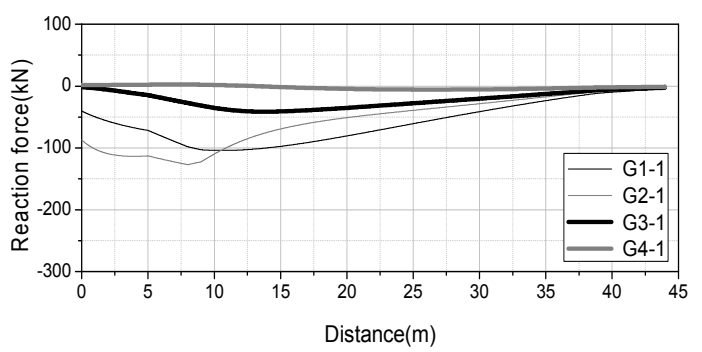

(c) $\mathrm{N}=1000$

Fig. 8 Reaction force response using data smoothing technique

Table 4 Comparison of estimated vehicle load considering the retardation effect

\begin{tabular}{|c|c|c|c|c|c|}
\hline & $\mathrm{N}$ & 1st axis & 2nd axis & 3rd axis & Total \\
\hline \multirow{3}{*}{10} & Vehicle & 60.525 & 119.447 & 119816 & 299788 \\
\hline & Load $(\mathrm{kN})$ & 00.325 & & & \\
\hline & error rate $(\%)$ & 0.875 & 0.461 & 0.153 & 0.071 \\
\hline \multirow{3}{*}{100} & Vehicle & 64832 & 114954 & 118350 & 298136 \\
\hline & $\operatorname{Load}(\mathrm{kN})$ & 04.832 & 114.934 & 110.030 & 290.150 \\
\hline & error rate $(\%)$ & 8.054 & 4.205 & 1.375 & 0.621 \\
\hline \multirow{3}{*}{200} & Vehicle & 69561 & 110111 & 16832 & 296504 \\
\hline & $\operatorname{Load}(\mathrm{kN})$ & 09.501 & 110.111 & 110.052 & 290.004 \\
\hline & error rate $(\%)$ & 15.934 & 8.241 & 2.640 & 1.166 \\
\hline \multirow[t]{2}{*}{500} & $\begin{array}{c}\text { Vehicle } \\
\text { Load }(\mathrm{kN})\end{array}$ & 95.267 & 85.115 & 109.863 & 290.244 \\
\hline & error rate $(\%)$ & 58.778 & 29.071 & 8.447 & 3.252 \\
\hline \multirow[t]{2}{*}{1000} & $\begin{array}{c}\text { Vehicle } \\
\text { Load }(\mathrm{kN})\end{array}$ & 158.459 & 42.058 & 86.860 & 287.376 \\
\hline & error $\operatorname{rate}(\%)$ & 164.098 & 64.952 & 27.617 & 4.208 \\
\hline
\end{tabular}


affected by the retardation effect, those of total load were comparatively smally affected by the retardation effect. Therefore, The estimation of total load with developed B-WIM system is deemed to be possible to use when there are retardation effects.

\subsubsection{The Influence of Time Delay for Estimation of Vehicle Load}

The B-WIM system algorithm developed in this study does not need axial sensors. It is therefore necessary to investigate how the estimation of vehicle total load and axial load is influenced when the entry time of axle and vehicle is not accurately portrayal. Vehicle total load and axial load were compared by varying time delays. Table 5 shows the resulting difference in entry distance, with $0.5 \mathrm{~m}, 1 \mathrm{~m}$ and $2 \mathrm{~m}$ difference.

As shown in Table 5, the bigger the influence of time delay, the bigger the errors become. Therefore the estimation of total load and axial load is deemed impossible with time delay. The entry time of vehicles need to be accurately measured in order to measure vehicle load.

\subsubsection{Estimation of Vehicle Load According to Vehicle Speed}

The B-WIM system algorithm was verified with moving vehicle load analysis. The vehicle load used for numerical analysis is shown in Fig. 9. The front axle weight of the vehicle was 6 ton, and the rear axle weight was 12 ton. The speed of the vehicle was set at $3.6 \mathrm{~km} / \mathrm{h}$, $80 \mathrm{~km} / \mathrm{h}, \quad 100 \mathrm{~km} / \mathrm{h}, \quad 120 \mathrm{~km} / \mathrm{h}$ respectively for numerical analysis.

Fig. 10 13 show the reaction force responses at P1 for each vehicle speed. When the vehicle passes the bridge at the speed of $3.6 \mathrm{~km} / \mathrm{h}$, the reaction force response is less influenced from the noise, as shown in Fig. 10. Fig. 11 13
Table 5 Comparison of estimated vehicle load considering the influence of time delay

\begin{tabular}{cccccc}
\hline \multicolumn{2}{c}{ Time delay } & 1st axis & 2nd axis & 3rd axis & Total \\
\hline \multirow{2}{*}{$0.5 \mathrm{~m}$} & $\begin{array}{c}\text { Vehicle } \\
\text { Load(kN) }\end{array}$ & 50.604 & 68.909 & 173.990 & 293.503 \\
\cline { 2 - 6 } & error rate(\%) & 15.661 & 42.576 & -44.992 & 2.166 \\
\hline \multirow{2}{*}{$1 \mathrm{~m}$} & $\begin{array}{c}\text { Vehicle } \\
\text { Load(kN) }\end{array}$ & 41.869 & 17.795 & 228.206 & 287.869 \\
\cline { 2 - 6 } & error rate(\%) & 30.219 & 85.171 & -90.171 & 4.044 \\
\hline \multirow{2}{*}{$2 \mathrm{~m}$} & $\begin{array}{c}\text { Vehicle } \\
\text { Load(kN) }\end{array}$ & 26.575 & 33.991 & 205.755 & 266.321 \\
\cline { 2 - 6 } & error rate(\%) & 55.708 & 71.674 & -71.462 & 11.226 \\
\hline
\end{tabular}

show that the noise was increased by growth of vehicle speed. This means that there are interaction between the bridge and the vehicle based on the vehicle's excitation force which is increased according to the speed of the vehicle.

Table 6 shows the results of total load and axial load estimation using the developed B-WIM system algorithm in this study. The total weights of the vehicle have been estimated with a small errors as less than $1 \%$ when the estimation was executed with considering the influence of dynamic load by the vehicle speed.

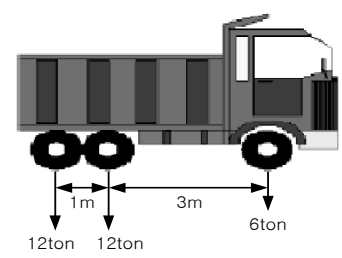

Fig. 9 Vehicle load

Table 6 Comparison of vehicle Load based on vehicle speed

\begin{tabular}{cccccc}
\hline \hline & & 1st axis & 2nd axis & 3rd axis & Total \\
\hline \hline \multirow{2}{*}{$\begin{array}{c}\text { Vehicle } \\
\text { Load(kN) }\end{array}$} & 61.44 & 121.02 & 117.58 & 300.03 \\
\cline { 2 - 6 } & $\begin{array}{c}\text { error rate } \\
(\%)\end{array}$ & 2.397 & 0.846 & 2.019 & 0.010 \\
\hline $\begin{array}{c}\text { Vehicle } \\
\text { Load(kN) }\end{array}$ & 63.74 & 115.68 & 121.28 & 300.71 \\
\hline $\begin{array}{c}\text { error rate } \\
(\%)\end{array}$ & 6.240 & 3.600 & 1.068 & 0.235 \\
\hline $\begin{array}{c}\text { Vehicle } \\
\text { Load(kN) }\end{array}$ & 58.49 & 113.98 & 128.06 & 300.52 \\
\hline $\begin{array}{c}\text { error rate } \\
(\%)\end{array}$ & 2.517 & 5.021 & 6.714 & 0.174 \\
\hline $\begin{array}{c}\text { Vehicle } \\
\text { Load(kN) }\end{array}$ & 65.45 & 99.56 & 136.49 & 301.50 \\
\hline $\begin{array}{c}\text { error rate } \\
(\%)\end{array}$ & 9.090 & 17.037 & 13.741 & 0.500 \\
\hline
\end{tabular}




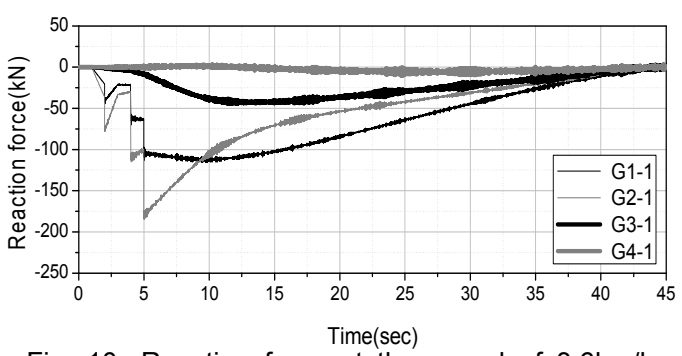

Fig. 10 Reaction force at the speed of $3.6 \mathrm{~km} / \mathrm{h}$

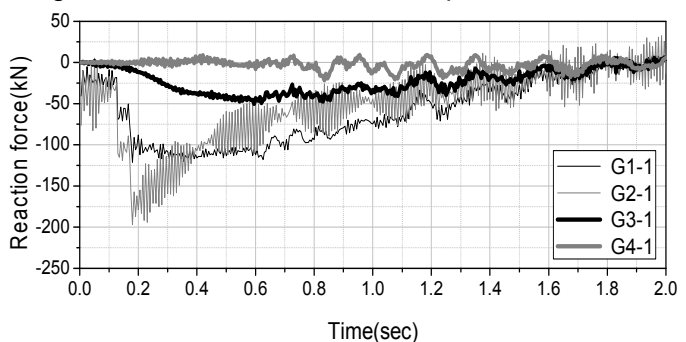

Fig. 11 Reaction force at the speed of $80 \mathrm{~km} / \mathrm{h}$

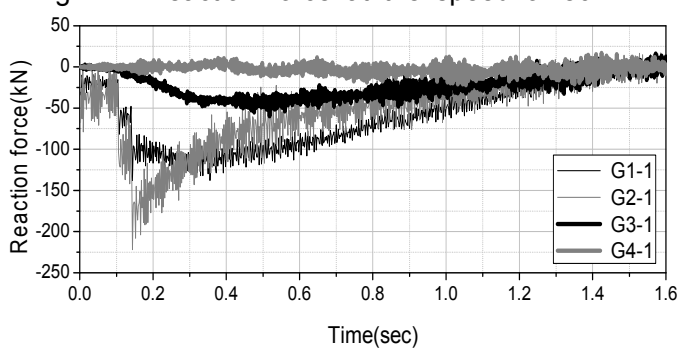

Fig. 12 Reaction force at the speed of $100 \mathrm{~km} / \mathrm{h}$

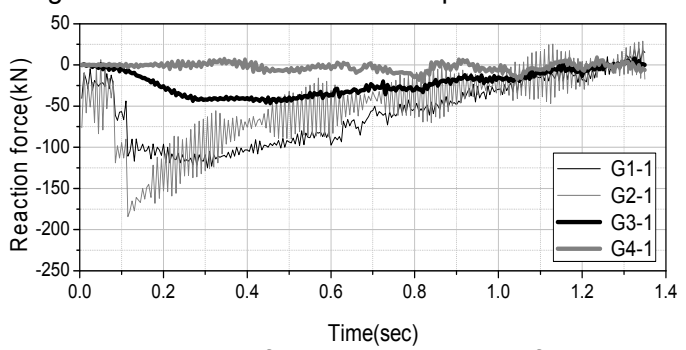

Fig. 13 Reaction force at the speed of $120 \mathrm{~km} / \mathrm{h}$

\subsubsection{Estimation of Vehicle Load Based on Changes in Vehicle Speed}

The vehicle speed can be changed while the vehicle passes through a bridge. Therefore, the total weight and axial weight of vehicle should be estimated using the average speed of the vehicle for using developed B-WIM system. The average speed of the vehicle was used to estimate the total weight and axial weight when the vehicle speed was changed.

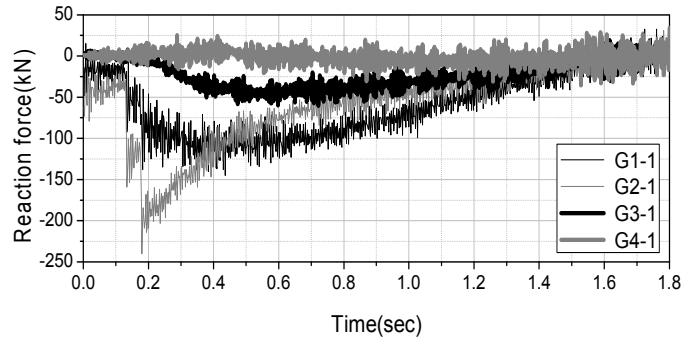

Fig. 14 Reaction force response $(80 \mathrm{~km} / \mathrm{h} \rightarrow 100 \mathrm{~km} / \mathrm{h})$

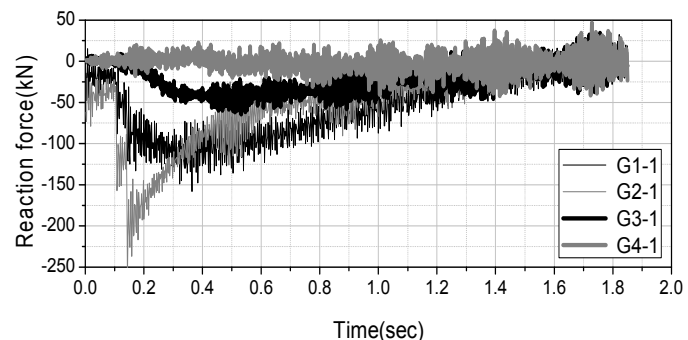

Fig. 15 Reaction force response $(100 \mathrm{~km} / \mathrm{h} \rightarrow 80 \mathrm{~km} / \mathrm{h})$

Table 7 Comparison of vehicle load based on changes in vehicle speed

\begin{tabular}{cccccc}
\hline & & 1st axis & 2nd axis & 3rd axis & Total \\
\hline $\begin{array}{c}80 \mathrm{~km} / \mathrm{h} \\
\rightarrow\end{array}$ & $\begin{array}{c}\text { Vehicle } \\
\text { Load(kN) }\end{array}$ & 63.082 & 91.289 & 156.717 & 311.088 \\
\cline { 2 - 6 } $100 \mathrm{~km} / \mathrm{h}$ & error rate(\%) & 5.137 & 23.926 & 30.598 & 3.696 \\
\hline $\begin{array}{c}100 \mathrm{~km} / \mathrm{h} \\
->\end{array}$ & $\begin{array}{c}\text { Vehicle } \\
\text { Load(kN) }\end{array}$ & 73.502 & 162.819 & 46.485 & 282.806 \\
\cline { 2 - 6 } $80 \mathrm{~km} / \mathrm{h}$ & error $\operatorname{rate}(\%)$ & 22.503 & 35.683 & 61.263 & 5.731 \\
\hline
\end{tabular}

It takes 1.44 seconds for a vehicle passing through a $40 \mathrm{~m}$ bridge under $100 \mathrm{~km} / \mathrm{h}$ velocity. And the maximum change of velocity can be estimated as $11.6 \mathrm{~km} / \mathrm{h}$ because it is usually needed about 12.4 seconds to change the velocity from zero to $100 \mathrm{~km} / \mathrm{h}$ even though there are differences according to kinds of vehicles [9]. Therefore, in this study, a numerical analysis was executed for identifying the influence by vehicle velocity changes of $20 \mathrm{~km} / \mathrm{h}$ which is higher than average velocity changing.

Fig. 14 shows the reaction force response in the case of changing the vehicle speed from $80 \mathrm{~km} / \mathrm{h}$ to $100 \mathrm{~km} / \mathrm{h}$. And Fig. 15 shows the reaction force response in case of changing from $100 \mathrm{~km} / \mathrm{h}$ to $80 \mathrm{~km} / \mathrm{h}$. 
Table 7 shows the results of the estimation of axial weight and total weight in case of vehicle speed change. Axial load is difficult to accurately estimate as shown in the Table 7 when the vehicle's speed are changed. On the other hand, the total load estimation is deemed to be relatively reliable.

3.2 B-WIM System Verification with Numerical Analysis Model of 3-Span PSC Bridge

\subsubsection{Model Construction for 3-Span PSC Bridge}

Numerical analysis of a 3-span PSC bridge was performed to investigate the applicability of the B-WIM system algorithm to the 3-span continuous bridge. The 3-span continuous bridge was builded with $12 \mathrm{~m}$-wide, with length of $40+45+40 \mathrm{~m}$. The element used in numerical analysis was Beam element. Fig. 16 represents the numerical model. The dynamic characteristic of the model is shown in Table 8 .

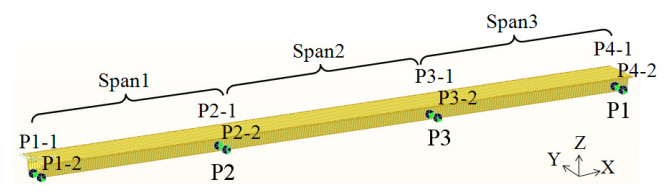

P1

Fig. 16 Numerical analysis model (3-span PSC bridge)

Table 8 Dynamic characteristics of 3-span PSC bridge (mode shape, natural frequency)

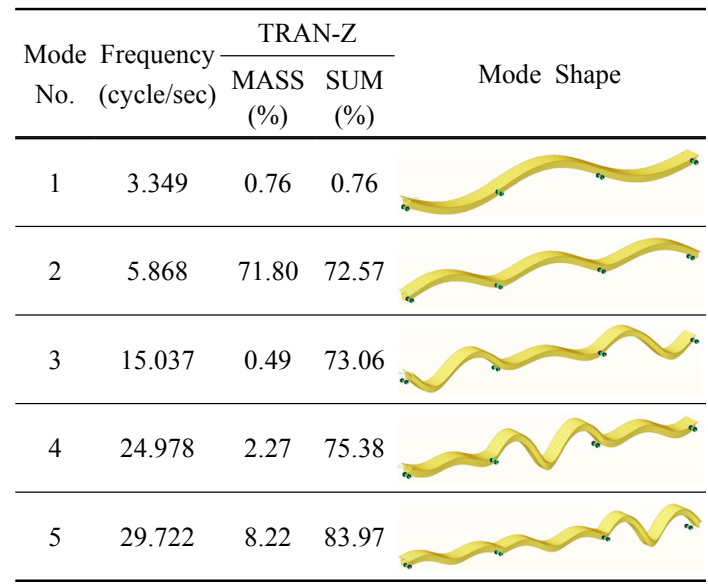

The vehicle load used in the numerical analysis was represented in Fig. 9 as same with the single span bridge. The vehicle speed was respectively $3.6 \mathrm{~km} / \mathrm{h}, \quad 80 \mathrm{~km} / \mathrm{h}, \quad 100 \mathrm{~km} / \mathrm{h}$ and $120 \mathrm{~km} / \mathrm{h}$ for numerical analysis.

\subsubsection{Estimation of Vehicle Load Using the} B-WIM System

Moving vehicle load analysis was performed, when the vehicle passes on a moving line as shown in Fig. 17. The influence line of reaction force at bridge supporting points are shown in Fig. 18.

The reaction force responses at supporting points are shown in Fig. 19 22. The results of the total load and axial load estimation using the developed B-WIM system algorithm in this study are shown in Table 9. In Table 9, the errors of estimated total load does not exceed $1 \%$. Therefore, the estimation of vehicle load on multi-span continuous bridges is deemed to be possible.

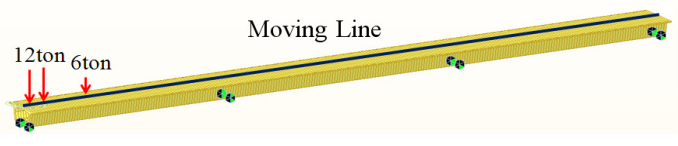

Fig. 17 Location of vehicle load

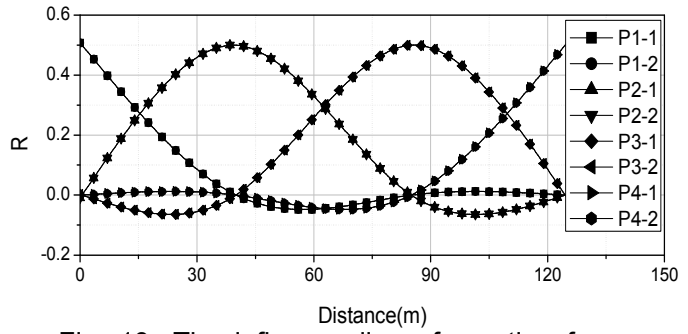

Fig. 18 The influence line of reaction force

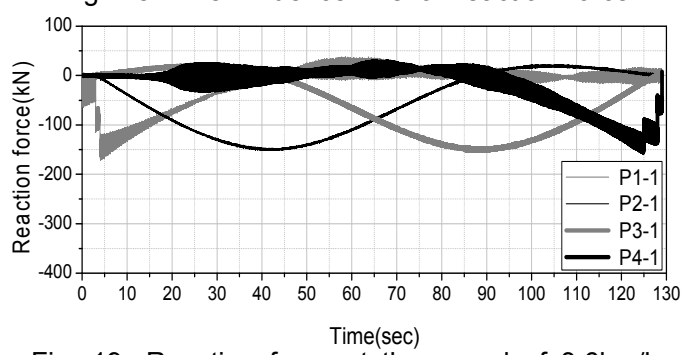

Fig. 19 Reaction force at the speed of $3.6 \mathrm{~km} / \mathrm{h}$ 


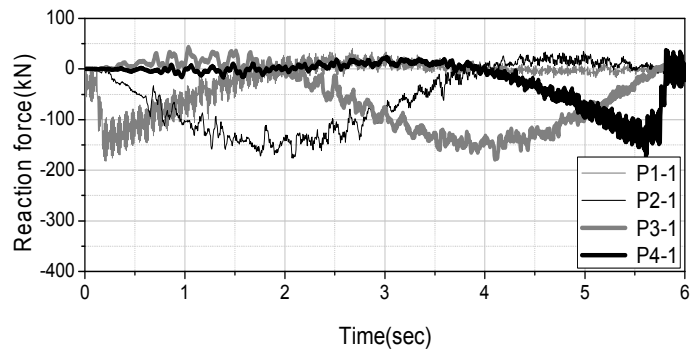

Fig. 20 Reaction force at the speed of $80 \mathrm{~km} / \mathrm{h}$

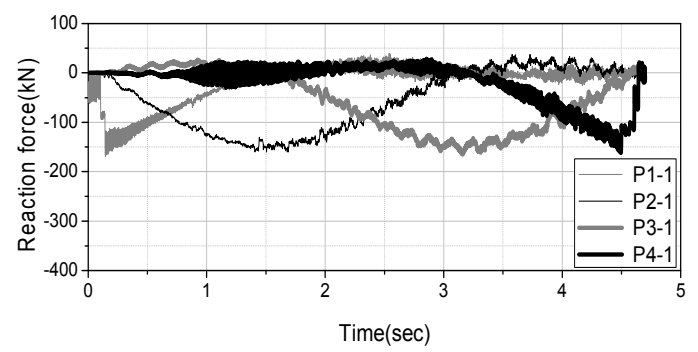

Fig. 21 Reaction force at the speed of $100 \mathrm{~km} / \mathrm{h}$

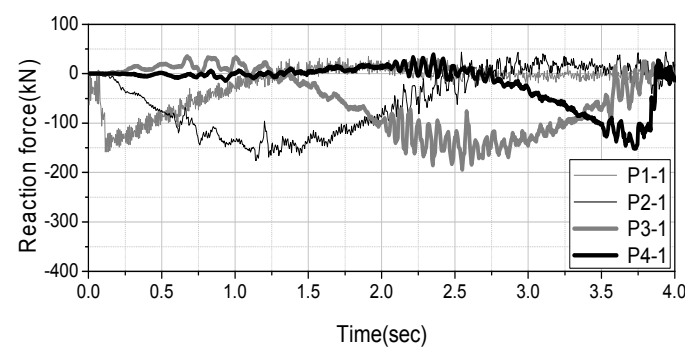

Fig. 22 Reaction force at the speed of $120 \mathrm{~km} / \mathrm{h}$

Table 9 Comparison of vehicle load based on vehicle speed

\begin{tabular}{|c|c|c|c|c|c|}
\hline & & 1st axis & 2nd axis & 3rd axis & Total \\
\hline \multirow[t]{2}{*}{$3.6 \mathrm{~km} / \mathrm{h}$} & $\begin{array}{c}\text { Vehicle } \\
\text { Load }(k N)\end{array}$ & 61.17 & 121.11 & 117.75 & 300.03 \\
\hline & error rate $(\%)$ & 1.953 & 0.922 & 1.872 & 0.011 \\
\hline \multirow[t]{2}{*}{$80 \mathrm{~km} / \mathrm{h}$} & $\begin{array}{c}\text { Vehicle } \\
\text { Load(kN) }\end{array}$ & 68.18 & 108.28 & 124.80 & 301.26 \\
\hline & error rate $(\%)$ & 13.633 & 9.770 & 4.003 & 0.420 \\
\hline \multirow[t]{2}{*}{$100 \mathrm{~km} / \mathrm{h}$} & $\begin{array}{c}\text { Vehicle } \\
\operatorname{Load}(\mathrm{kN})\end{array}$ & 61.96 & 116.27 & 122.24 & 300.47 \\
\hline & error rate(\%) & 3.267 & 3.112 & 1.870 & 0.157 \\
\hline \multirow[t]{2}{*}{$120 \mathrm{~km} / \mathrm{h}$} & $\begin{array}{c}\text { Vehicle } \\
\operatorname{Load}(\mathrm{kN})\end{array}$ & 71.93 & 99.13 & 130.71 & 301.76 \\
\hline & error rate $(\%)$ & 19.878 & 17.396 & 8.927 & 0.588 \\
\hline
\end{tabular}

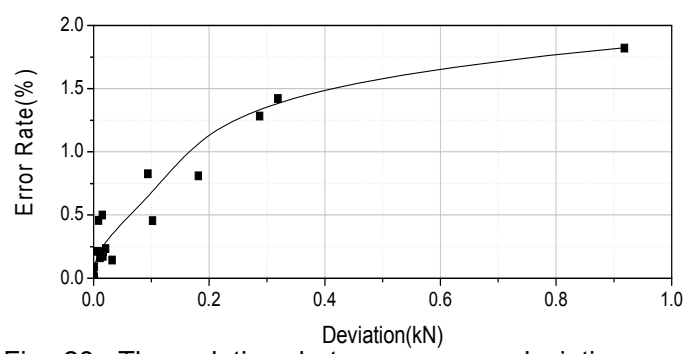

Fig. 23 The relation between mean deviation and error rate

\subsection{Result of Numerical Analysis}

The vehicle loads were estimated with consideration of the SNR, retardation, time delay and vehicle speed to identify the reasons of error rate. For identifying the relationship between the effect of mean deviation of the reaction force response and the error rate of estimated vehicle load, the relationship between two of them has been studied. The mean deviation is shown in Eq. (17). In the Eq. (17), $\mathrm{N}$ signifies the number of response signal, and $x_{i}$ is the response from the numerical moving load test and $\bar{x}$ is the theoretical response. The relationship between mean deviation and error rate is shown in Fig. 23. As shown in the Fig. 23 , it is observed that there are an increasing trend of error rate according to the increase of mean deviation. Therefore, the smaller mean deviation of reaction force response, the higher accurate estimation of vehicle load become.

$$
D=\frac{\sum_{i=1}^{N}\left(x_{i}-\bar{x}\right)}{N}
$$

\section{Conclusion}

In this study, a B-WIM system was developed to estimate the vehicle load passing through a bridge. Not a strain signal which is normally used in the conventional B-WIM system but reaction force responses at bridge supporting points is used in developed B-WIM system in 
this study. The conventional system is applicable only to simple slab bridges, slab bridges fixed at both ends or other bridges with similar effect. However, it is confirmed that the developed B-WIM system can be used for estimation of vehicle load on a single-span bridge and a 3-span continuous beams with numerical test. The moving load analysis was performed, and the vehicle load was estimated by using the developed B-WIM system. The error of estimation for axial weight was comparatively high. However, the results of estimation for total load of vehicle were reliable with small errors less than $1 \%$. Therefore, it is deemed to be possible to estimate the total vehicle weight using the developed B-WIM system in this study.

Error analysis were performed according to changes of SNR, retardation, time delay and vehicle's speed to confirm the usability of the developed B-WIM system. It has been observed that the error rate of estimated total vehicle weight is increased according to the increase of mean deviation of measured reaction force response from the results of error analysis. Therefore, it is expected to estimate more accurate vehicle load by reducing measurement error in field test.

The developed B-WIM system will be verified with a reaction forces from a existing bridge in further studies. Moreover, the system will be corrected to exactly estimate not only the total weight but also axis weights in further works.

\section{Acknowledgement}

This work was supported by the National Research Foundation of Korea (NRF) grant funded by the Korea government (MEST) (2012R1A1A2005132).

\section{References}

[1] Laboratoire Central des Ponts et Chaussees, "Weigh-in-motion of axles and vehicles for
Europe(WAVE)," RTD project, RO-96-SC, 403 (2001)

[2] F. Moses, "Weigh-in motion system using instrumented bridge," Transportatin Engineering Journal, ASCE, Vol. 105, pp. 233-249 (1979)

[3] S. S. Law, T. H. T. Chan and Q. H. Zeng, "Moving force identification: A time domain method," Journal of Sound and Vibration, Vol. 201, No. 1, pp. 1-22 (1997)

[4] E. S. Hwang, D. B. Bae, K. S. Jung and J. B. Jo, "Analysis of truck traffic characteristics using BWIM system," Journal of Korean Society of Steel Construction, Vol. 11, No. 2, pp. 223-232 (1999)

[5] Korea Highway Corporation, "A study for live load formulation on highway bridges," A Research Paper of Korea Highway Corporation (2001)

[6] M. S. Park, J. W. Lee, S. K. Kim and B. W. Jo, "Vehicle load analysis using bridgeweigh-in-motion system in a cable stayed bridge," Journal of the Earthquake Engineering Society of Korea, Vol. 10, No. 6, pp. 1-8 (2006)

[7] B. H. Kim, M. S. Park, K. S. Yeo and S. J. Kim, "Sensitivity-based BWIM system using dynamic strain responses of bridge deck plate," Transactions of the Korean Society for Noise and Vibration Engineering, Vol. 20, No. 7, pp. 620-628 (2010)

[8] A. R. S. Han and S. B. Shin, "Application for a BWIM algorithm using density estimation function and average modification factor in the field test," Journal of the Korea institute for structural maintenance inspection, Vol. 15, No. 2, pp. 70-78 (2011)

[9] M. S. Kim and K. H. Kim, "Prediction of vehicle acceleration performance and fuel economy," Transactions of the Korean Society of Mechanical Engineers, Vol. 33, No. 10, pp. 861-870 (1993) 